\title{
REPLACING THE ICE BY ELECTRIC MOTOR OF THE IVECO 150E EUROCARGO HARD- PRESS GARBAGE TRUCK
}

\author{
Dr. Zsolt TIBA \\ University of Debrecen, \\ Faculty of Engineering \\ Debrecen, Hungary \\ tiba@eng.unideb.hu
}

\author{
Dr. Géza HUSI \\ University of Debrecen, \\ Faculty of Engineering \\ Debrecen, Hungary \\ husigeza@eng.unideb.hu
}

\author{
Jozsef KERTESZ \\ University of Debrecen, \\ Faculty of Engineering \\ Debrecen, Hungary \\ kertesz_jozsef@eng.unid \\ eb.hu
}

\author{
Zsolt BÉKÉSI \\ University of Debrecen, \\ Faculty of Engineering \\ Debrecen, Hungary \\ zsolt.bekesi@eng.unideb. \\ $\underline{\mathrm{hu}}$
}

\begin{abstract}
A garbage truck is a specially designed vehicle to collect small quantities of waste and haul the collected waste to a solid waste treatment facility. These trucks powered by diesel engine are a common sight in most urban areas. The main features of them are noisy, smelly and contaminating the environment by emission respectively. Some of these harmful effects may be reduced or eliminated by replacing the diesel engine by an electric motor. In this paper we consider the technical options of replacing in terms of vehicle dynamic and bearing capability of the modified drive train parts. The rebuilding is supported by the GOP-1.1.1-11-2012-0617 Economy Developing Operative Programme implemented at the Electrical Engineering and Mechatronics Department, Faculty of Engineering, University of Debrecen.
\end{abstract}

Keywords- power density, gradeability, torque demand, load consideration

\section{ELIGIBLE RESOLUTIONS FOR DRIVETRAIN MODIFICATION}

\subsection{Power density and storage density}

Fig. 1 shows the power and energy-storage densities for various propulsion concepts. Both the power density $(\mathrm{W} / \mathrm{kg})$ and the energy-storage density $(\mathrm{Wh} / \mathrm{kg}$ ) of the combined engine/energy-storage system must be high to achieve the desired performance (acceleration, speed).

The vehicle's operating time - and thus the operating range which can be covered before the energy-storage device must be replenished (renewed/ refilled/recharged) - is a function of the energy-storage density, the power requirement, and the vehicle weight.

Although the power-to-weight ratios combining with high energy-storage densities (period of operation per tank of fuel) make internal-combustion engines (ICE) particularly suitable for vehicular applications, the torque curves are less satisfactory, see Fig. 2. Thus a transmission unit is required for both the transfer and the conversion of torque. The unit must be capable of transmitting torque for starting off while incorporating various torque-conversion ratios (for ascending gradients and selecting different speed ranges). Electric driven vehicles also may need a transmission due to the limitations imposed by the allowed current at starting.

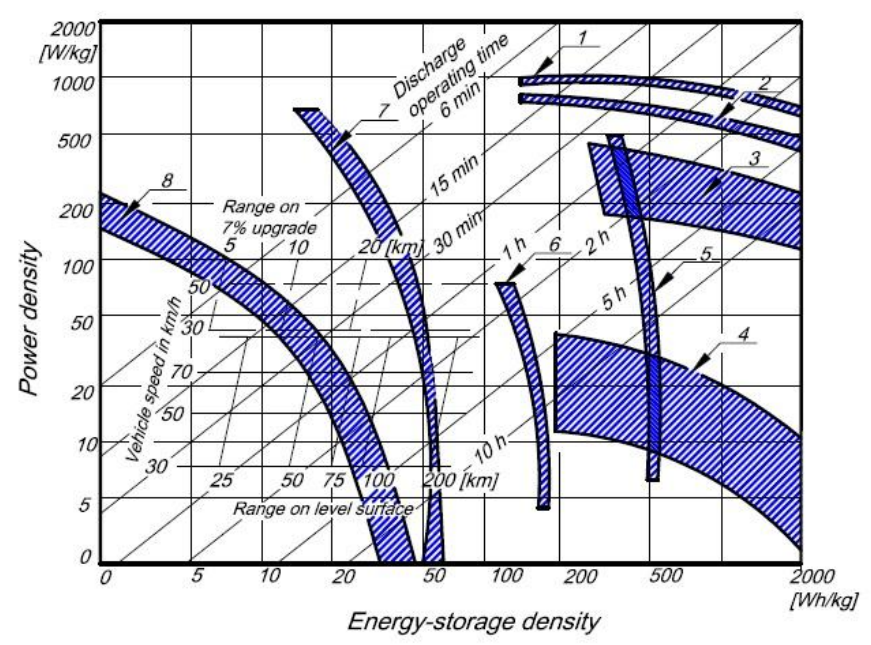

Fig. 1: Power and energy-storage densities for various propulsion concepts [1]

1 Gas turbine, 2 Internal combustion engine, 3 Externalcombustion engine, 4 Electric motor with fuel cell, 5 Lithiumchloride battery, 6 Zinc-air battery, 7 Nickel-cadmium battery, 8 Lead acid battery. 


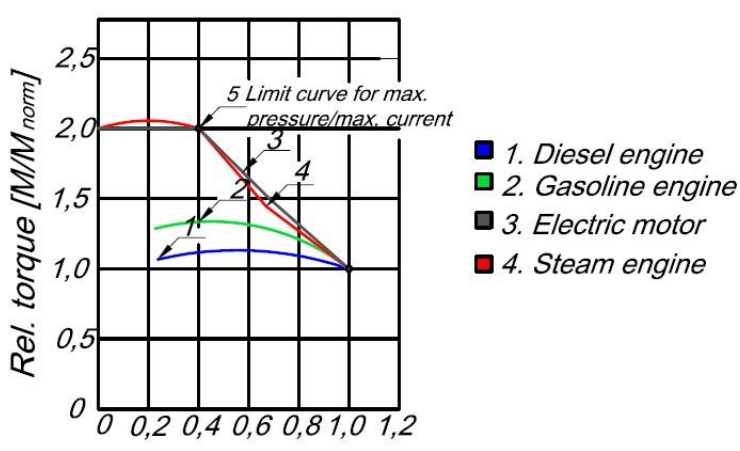

Rel. rotational speed [ $\left.\mathrm{n} / \mathrm{n}_{\text {norm }}\right]$

Fig. 2: Relative torques for various power units [2]

\section{2. $\quad$ Choice of replacing propulsion system}

In the urban area when collecting garbage, the average speed of the vehicle is approximately $3-4 \mathrm{~km} / \mathrm{h}$, due to the nonstationary operation. If the solid waste treatment facility situates close to the urban area, inside the operating range of an electrical vehicle, it is expedient to replace the internal combustion engine of the truck by electric motor and Lithiumchloride battery, with or without transmission respectively. This way, the harmful effects of the diesel engine such as noisy, smelly and contamination of the environment by emission may be eliminated or reduced.

\section{REPLACING THE ICE BY ELECTRIC MOTOR}

The rebuilt vehicle must be capable of effecting the transition from a stationary to a mobile state. Once in motion, it must be able to ascend gradients and accelerate to the desired cruising speed with a reasonable degree of alacrity.

In this paper we consider the technical options of replacing in terms of vehicle dynamic and bearing capability of the modified drive train parts. Only the engine, transmission and universal joint shaft may be covered in the modification. The suspension and the rear axle with the differential are not affected.

\subsection{Vehicle dynamic consideration}

2.1.1. Introduction of the drivetrain of the IVECO 150E Eurocargo Hard-Press Garbage Truck

A garbage truck is a specially designed vehicle to collect and haul communal waste to a solid waste treatment facility. These garbage trucks are a common sight in most urban areas. The main features of the truck powered by 6 cylinders 5.88 litres capacity diesel engine (see Fig. 3) are the following [3]:
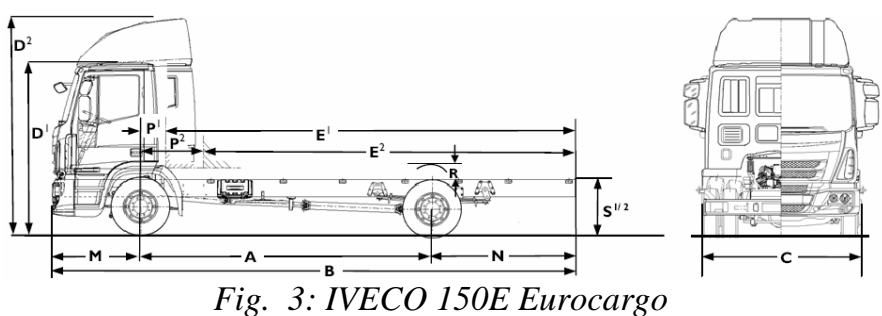

Engine: Iveco Tector

$\begin{array}{ccc}\mathrm{P} & 217 / 160[\mathrm{PS} / \mathrm{kW}] & \\ \mathrm{n} & 2700 & {\left[\mathrm{~min}^{-1}\right]} \\ \mathrm{M} & 680 & {[\mathrm{Nm}]}\end{array}$

$(1200$

$\left.\min ^{-1}-2100 \min ^{-1}\right)$

Gearbox: ZF 6S700 Manual

Gear ratios:

$\begin{array}{ll}1^{\text {st }} & 6.02 \\ 2^{\text {nd }} & 3.32 \\ 3^{\text {rd }} & 2.07 \\ 4^{\text {th }} & 1.40 \\ 5^{\text {th }} & 1.00 \\ 6^{\text {th }} & 0.79\end{array}$

Geared speed: $\quad 122 \mathrm{~km} / \mathrm{h}$

Differential: Meritor MS 10-164 Hypoid, ratio: 4.56

Maximum bodyload: $\quad 150 \mathrm{kN}$

Gradeability: $\quad 25 \%$

Tyres: 285/70R19.5

Rolling diameter: $\quad 895 \mathrm{~mm}$

Deflection angle of the $U$ joints in stationary state: $4^{\circ}$

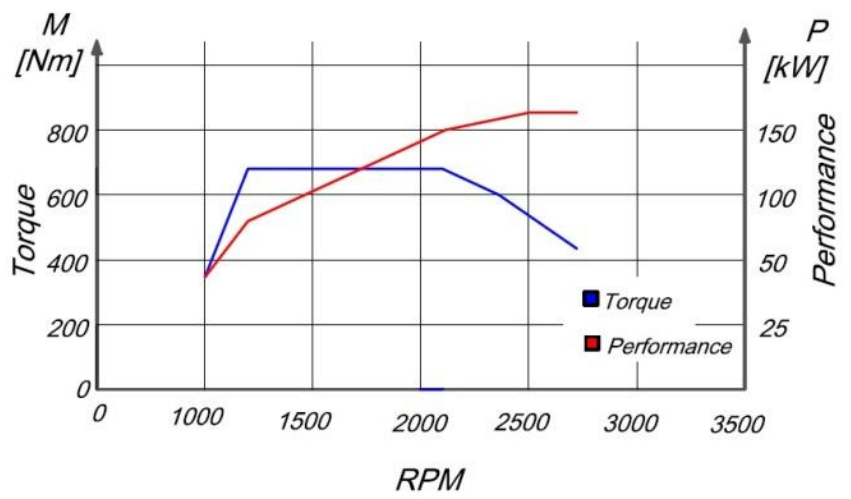

Fig. 4: Engine characteristic

\subsubsection{Dynamics of linear motion}

The tractive force of the vehicle has to overcome the total running resistance at a given vehicle speed. The rest of it may be utilized for speed-up (acceleration).

The equation of equilibrium of tractive force is as follows:

$$
F_{t r}=F_{w}+F_{a c c}
$$

(1)

where: $F_{w}=F_{R}+F_{D}+F_{G}$ 
$F_{w}$ total rolling resistance, $\left(F_{R}\right.$ rolling resistance, $F_{D}$ aerodynamic drag, $F_{G}$ gradient resistance)

\subsubsection{Required torque of the universal joint shaft} The maximum required torque of the universal joint shaft is arising when ascend gradient. With the maximum bodyload the vehicle according to its specification has to overcome at least a gradient of 140 (it corresponds to $25 \%$ gradeability).

The gradient resistance is calculated as:

$$
F_{G}=G \sin \alpha \approx 36 k N
$$

The required torque of the driven wheel:

$$
M_{\text {wheel }}=F_{G} R_{\text {wheel }} \approx 16 \mathrm{kNm}
$$

The maximum required torque of the universal joint shaft:

$$
M_{\text {shaft req. }}=\frac{M_{\text {wheel }}}{i_{\text {diff }}} \approx 3.5 \mathrm{kNm}
$$

(5)

\subsubsection{Determining the power requirement of the} electric motor

The electric motor power requirement depends on whether a transmission is applied or not.

If transmission is applied, the torque requirement on the shaft may be satisfied by appropriate choosing of the gear ratio. The motor power may affect the maximum speed of the vehicle.

If there is no transmission applied, and the electric motor is connected directly to the universal joint shaft, the torque required has to be produced by the electric motor.

\subsubsection{Checking the original drivetrain for gradeability} The torque of the diesel engine from $\mathrm{n}=1200 \mathrm{rpm}$

$$
M_{\text {ICE }}=680 \mathrm{Nm}
$$

The torque on the universal joint shaft in the first gear:

$$
M_{\text {shaft ICE }}=M_{I C E} i_{1^{\text {st } \text { gear }}}=4.2 \mathrm{kNm}
$$

$$
M_{\text {shaft ICE }}>M_{\text {shaft req. }}
$$

As it can be seen, the original drivetrain effects the $25 \%$ gradeability requirement, moreover it has traction force left for acceleration.

2.1.6. Checking the electric motor for gradeabiliy Data of the available three-phase star connected electric motor:

$$
P=110 k W
$$

$$
\begin{aligned}
& U=350 \mathrm{~V} \\
& n=2880 \mathrm{~min}^{-1} \\
& M_{\text {nom }}=320 \mathrm{Nm} \\
& M_{\text {max }}=10 M_{\text {nom }}=3.2 \mathrm{kNm} \quad \text { (in the rpm range } \\
& \text { from } 0 \text { to } 2880 \\
& \min ^{-1}, \quad \text { with } \\
& \text { frequency control, } \\
& \text { see Fig. 5) } \\
& M_{\text {el.mot }}<M_{\text {shaft req. }}
\end{aligned}
$$

As it can be seen, the electric motor without transmission does not effect the $25 \%$ gradeability requirement.

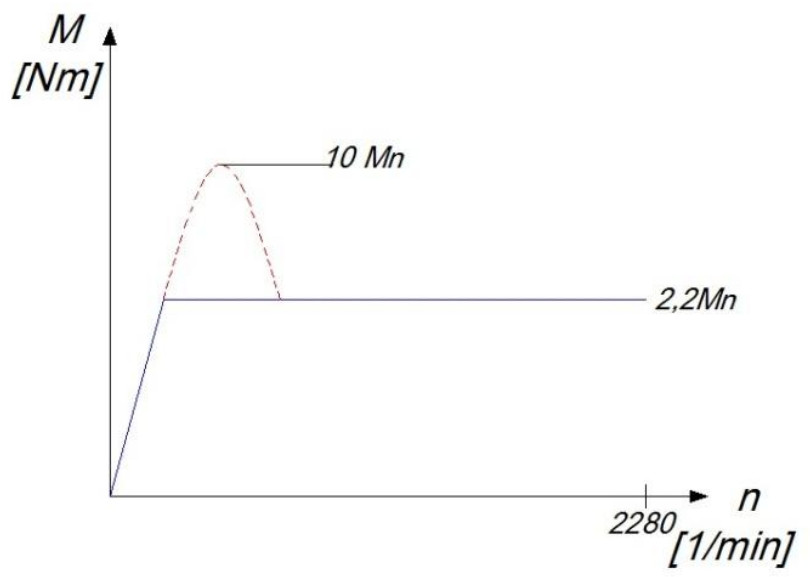

Fig. 5: Electric motor characteristic

\subsection{The gradeability of the vehicle without transmission}

The torque of the driven wheel:

$$
M_{\text {wheel }}=M_{\text {el.mot }} i_{\text {diff }}=14.6 \mathrm{kNm}
$$

Tractive force on the driven wheel:

$$
F_{\text {trac }}=\frac{M_{\text {wheel }}}{R_{\text {wheel }}} \approx 32.6 \mathrm{kN}
$$

The angle of gradient may be overcome by this tractive force:

$$
\alpha=\arcsin \frac{F_{t r a c}}{G} \approx 12.5^{\circ} \text { (gradeability: } 22 \% \text { ) }
$$




\subsection{The top speed of the vehicle powered by electric motor}

The equation of equilibrium of tractive force at top speed on level road is the following:

$$
\begin{aligned}
& F_{\text {trac }}=F_{w}=F_{R}+F_{D} \\
& (10) \\
& F_{\text {trac }}=32.6 \mathrm{kN}
\end{aligned}
$$

\section{Rolling resistance}

The rolling resistance is the product of deformation processes which occur at the contact patch between tire and road surface. The coefficient of rolling resistance at low speed for pneumatic truck tires on concrete, asphalt is approximately $f_{0} \approx 0.008$ [2]. The rolling resistance depends among others on the vehicle speed. At about 100 $\mathrm{km} / \mathrm{h}$ vehicle speed the rolling resistance is approximately $50 \%$ higher than $f_{0}$, consequently $f \approx 0.012$.

$$
F_{R}=f G=1.8 k N
$$

Top speed consideration from the available tractive force aspect.

If the maximum tractive force is available continuously due to the frequency control of the electric motor, the top speed is limited by the aerodynamic drag. From the Eq. 10 the equation of equilibrium of tractive force is as follows (there is no force left for acceleration):

$$
F_{D}=F_{\text {trac }}-F_{R}
$$$$
\text { where: } F_{D}=0.5 \rho C_{w} A\left(v+v_{0}\right)^{2}
$$

$$
C_{w}=1.2
$$

drag coefficient for trucks [2]

air density at $200 \mathrm{~m}$ altitude

$$
\rho=1.2 \mathrm{~kg} / \mathrm{m}^{3}
$$

$$
A=13 m^{2}
$$

vehicle cross section

$$
v=\sqrt{\frac{F_{\text {trac }}-F_{R}}{0.5 \rho C_{w} A}}=57 \mathrm{~ms}^{-1}=206 \mathrm{~km} / \mathrm{h}
$$

Top speed consideration from the aspect of electric motor rpm

The vehicle speed results from the maximum rpm of the electric motor if the calculated speed is less than the speed limited by the aerodynamic drag.

$$
\begin{aligned}
& n_{\text {mot }}=2880 \mathrm{~min}^{-1}=48 \mathrm{~s}^{-1} \\
& n_{\text {wheel }}=10.5 \mathrm{~s}^{-1} \\
& v_{\text {wheel }} \approx 30 \mathrm{~ms}^{-1}=108 \mathrm{kmh}^{-1}
\end{aligned}
$$

The top speed of the vehicle is $108 \mathrm{~km} / \mathrm{h}$.

\subsection{Method of strength consideration}

The material and hence its properties of the drive train parts (such as the output shaft of the transmission, the input shaft of the differential, the electric motor shaft, $U$ joint forks) are not known. Since not being in possession of data mentioned above, real stressing procedure can not be carried out.

The applied method of strength consideration is the following: Analyzing the load produced by the universal joint shaft in the original drivetrain and in the original layout.

Determining the terminal position of the universal joint shaft in which it produces maximum the same load for the electric motor shaft as it is subjected to by a belt drive.

\subsubsection{Load consideration of the $U$ joint shaft drive} If the deflection angle of the $\mathrm{U}$ joints is $0^{\circ}$, the $\mathrm{U}$ joint shaft transmits only torque. If the deflection angle of the $U$ joints deviates from $0^{\circ}$ as in general case, supplementary forces arise in the joints causing concentrated moment on the shaft. This moment altering in the function of the angular displacement of the joint loads the connecting shafts of the differential, the transmission and the electric motor.

The maximum supplementary moment in the case of joint deflection [4]:

$$
M_{\text {ben }}=M_{\text {shaft ICE }} \operatorname{tg} \beta=4.2 \mathrm{kNm} \operatorname{tg} 4^{\circ}=2.9 \mathrm{kNm}
$$

\subsubsection{Load consideration of electric motor belt drive}

The electric motor is connected normally to the countershaft either directly through a coupling or by a belt drive. When connecting through a coupling, the motor shaft is subjected purely to torque. However in the case of belt drive the motor shaft is subject to torque and belt prestressing force.

Data of belt drive:

- the appropriate wedge belt section: SPB

- the minimum recommended datum diameter of the pulley: $d_{b}=140 \mathrm{~mm}$

- the peripheral force on the pulley:

$$
F_{p e r}=\frac{P_{\text {el.mot }}}{2 \pi n} \frac{1}{d_{b} / 2}=10.4 k N
$$


- the prestressing force of the belt drive loading the shaft:

$$
F_{\text {prestr }} \approx 2.4 F_{\text {per }}=25 \mathrm{kN}
$$

(16)

- $\quad$ the bending moment caused by the prestressing force:

$$
M_{\text {ben.el.mot }}=F_{\text {prestr }} l=3.75 \mathrm{kNm}
$$

(17)

arm on the shaft.

where: 1 is the length of the force

It can be seen, $M_{\text {ben.el.mot }}>M_{\text {ben }}$, so the U joint shaft can be connected directly to the electric motor shaft at the joint deflection angle of $4^{\circ}$ without damaging it, see Fig. 6.

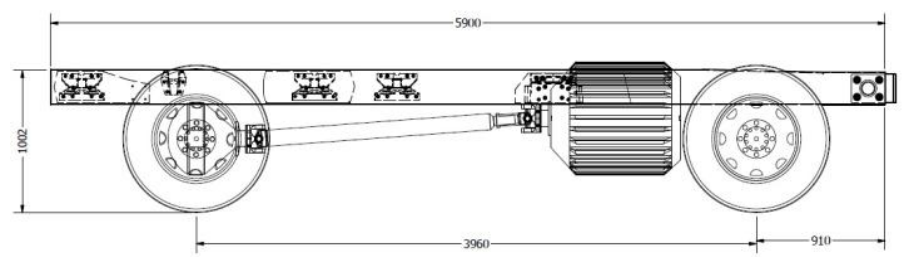

Fig. 6: Electric motor installation

III. SUMMARY
The rebuild of the IVECO 150E Eurocargo Hard-Press Garbage Truck supported by the GOP-1.1.1-11-2012-0617 Economy Developing Operative Programme covers the replacing the ICE by electric motor. There are several specifications of replacing, such as vehicle dynamics, strength consideration. Although the ICE can be replaced by the electric motor for the special task to collect small quantities of waste and haul the collected waste to a solid waste treatment facility, the rebuilt vehicle is not equivalent with the original one from vehicle dynamics aspects. The strength consideration, in the lack of the knowledge of materials and material properties, is based on the load assessment. If the load subjected to the parts after rebuilding is less than the load before rebuilding, the parts of the drivetrain won't damage.

\section{ACKNOWLEDGEMENT}

The work is supported by the TÁMOP-4.2.2.A-11/1/KONV2012-0041 project. The project is co-financed by the European Union and the European Social Fund.

\section{REFERENCES}

[1] "The Automobile and Air Pollution" US Department of Commerce (Morse Report)

[2] Mitschke M.: Dynamics of the motor vehicle Springer Verlag 1984

[3] IVECO Ltd. catalogue: PD/RB/150E22Truck/01/10

[4] VOITH High-Performance Universal Joint Shafts Products Catalogue. 